\title{
Household's Willingness to Pay for the Expansion of Mataasna Bayan and Sinisian East Marine Protected Area in Lemery, Batangas, Philippines
}

\author{
Buncag, Mark Joseph J. ${ }^{1}$, Capunitan, Mary Joy D. ${ }^{2}$, De Guzman, Angela M. ${ }^{2}$, \\ Ilagan, Ma. Patricia B. ${ }^{2}$, Magpantay, Angelica T ${ }^{2}$, Palma, Pauline Cielo P. ${ }^{2}$, Villanueva, Lea-Jim A. ${ }^{2}$ \\ ${ }^{I}$ Faculty, Palawan State University, Palawan, Philippines \\ ${ }^{2}$ University of the Philippines Los Baños, Philippines
}

\begin{abstract}
The study was conducted primarily to 1) identify the socio-economic and the knowledge, attitude and perception (KAP) factors that affect the WTP of the households; 2) determine the socio-economic factors affecting the KAP of households; and 3) determine the mean willingness to pay (WTP) of households of four barangays of Lemery, Batangas: Mataasna Bayan and Sinisian East as on-site barangays and Balanga and Sinisian West as off-site barangays of the Marine Protected Area (MPA). A total of 316 respondents were surveyed following the contingent valuation method (CVM). Results showed that the mean WTP of the respondents amounts to PhP 46.47 per month. Among factors influencing their WTP are KAP variables such as knowledge on MPA, knowledge on MPA as fish habitat, perception on the need of MPA protection led by the Barangay, perception if there is anything to be changed in MPA management, and socio-economic variables like gender, income-expenses ratio and distance from the MPA. Using the mean WTP, the computed social benefit derived by the on-site and off-site MPA communities from coral reef conservation-based from their WTP amounted to PhP 999,215.734 per year.
\end{abstract}

Keywords: Willingness to pay, Marine Protected Area, and Contingent Valuation Method

\section{INTRODUCTION}

Marine and coastal ecosystems are continually facing threats from both anthropogenic activities and natural sources. This poses a concern to the communities that are highly dependent on the goods and services that are being offered by these ecosystems. The establishment of Marine Protected Areas (MPA) is a management strategy adopted to protect marine and coastal habitats and organisms living in these habitats. In the Philippines, the Fisheries Code of 1998 mandated coastal municipalities to designate at least $15 \%$ of their total area as marine sanctuaries and marine protected areas. However, only $0.5 \%$ of municipal waters and 2.7$3.4 \%$ of coral reef areas are protected in no-takes MPAs (Weeks et al., 2010).

With the growing number of populations and the increasing number of coastal development activities, it is imperative that different field experts like biologists and economists continue to collaborate to study and investigate the potential values of the measures in protecting marine resources from anthropogenic activities (Hall et al., 2002) like fishing and tourism-related activities (Buncag, 2019). There are some ecosystem goods, and services that we derive from MPAs are non-use benefits and do not have an existing market price. This lack of existing market price poses difficulty in the quantification of economic values resulting in its under-valuation in the decision-making process and formulation of policies. To value these non-use benefits provided by the MPA, several methods, such as contingent valuation method (CVM) could be employed. This approach is a survey or questionnaire-based method which creates a hypothetical market to add monetary value to ecosystem goods and services by eliciting respondents' willingness to pay to access improved environmental quality or avoid a hypothetical reduction in environmental qualityto access improved environmental quality or avoid a hypothetical reduction in environmental quality.. The CVM survey collects useful data that can be utilized in the decision-making process and the formulation of policies and strategies for effective MPA management. 
In Lemery, Batangas, a marine protected area was established in response to the need to restore the damaged coral reef ecosystem in the area and increase biodiversity, thus ensuring stable food supply and sustainable livelihood among the residents. It is managed by the Marine Protected Area Management Body (MPA-MB), which determines policy direction and administers protection and conservation initiatives for the MPA. Partner organizations are also present who provide technical assistance and support. Despite efforts for effective management, the MPA continues to face challenges such as illegal fishing, pollution, and climate change impacts. The top three threats to the coastal resources are the residential and commercial development within the protected areas, climate change and severe weather, and energy production within the protected area. (Municipality of Lemery, 2013). As part of its management plan, the MPA-MB aimed to continue its protection and conservation efforts through effective and proper management measures and to expand the MPA in the area.

This study was conducted to determine the willingness to pay of households for the expansion of Mataasna Bayan and Sinisian East Marine Protected Area, Lemery, Batangas. Specifically, this aimed to identify the factors that may affect the willingness to pay of the households; determine the knowledge, attitude and perception of four barangays of Lemery Batangas on the importance of Mataasna Bayan and Sinisian East Marine Protected Area (MBSE MPA), and to determine the mean willingness to pay (WTP) of households of barangays Mataasna Bayan, Sinisian East, Balanga and Sinisian West in Lemery, Batangas. The results of this study will further contribute to the existing information on Mataasna Bayan and Sinisian East Marine Protected Area that will help the MBSE MPA Management Body in the decision-making process and in the development of management strategies. Determination of mean willingness to pay will represent the capability of the total household to pay for the expansion of the Mataasna Bayan and Sinisian East Marine Protected Area.

\section{MATERIALS AND METHODS}

\subsection{Study area}

The study was conducted in four coastal barangays of Lemery, Batangas,in May 2018. Mataasna Bayan and Sinisian East Marine Protected Area is located within the municipal waters of Lemery, Batangas. It covers an area of 6.5 has known as the no-take zone with a 100-meter buffer zone. It is directly under the jurisdiction of Barangays Mataasna Bayan and Sinisian East. It is geographically bounded on the west by Barangay Sinisian West and the east by Barangay Balanga. Figure 1 shows the location map of the study area. 


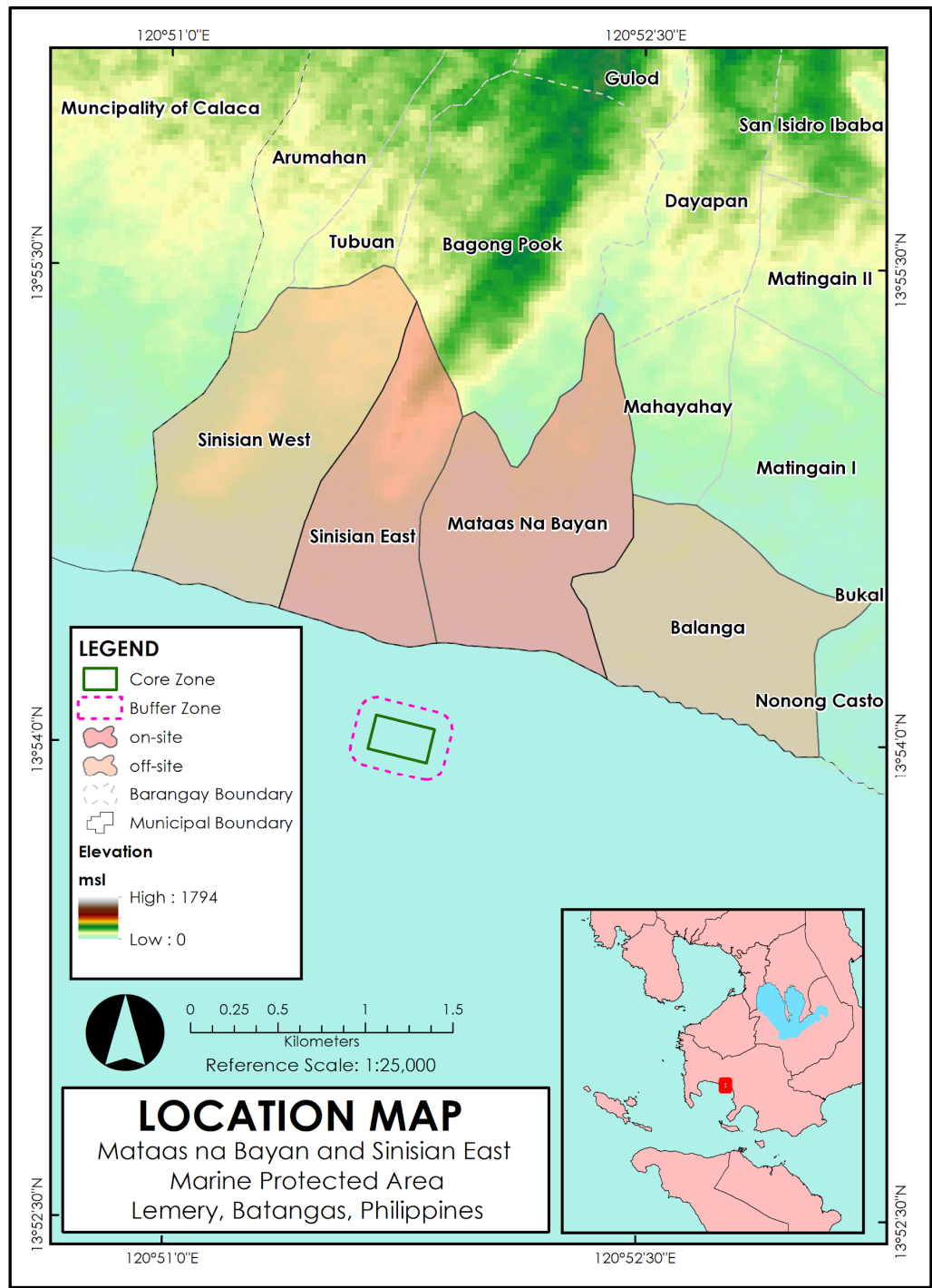

Figure 1 Location map of the Mataasna Bayan and Sinisian East Marine Protected Area

\subsection{Sampling Procedure}

The four sampled barangays had a total household population of 1,792 (MPDC, 2015). Using Cochran's formula with a 95\% confidence level, a total of 316 households were selected as respondents using stratified random sampling. The sample size was equally divided among the four barangays. During the conduct of the survey, a face-to-face interview was used. 


\subsection{Methodological Framework}

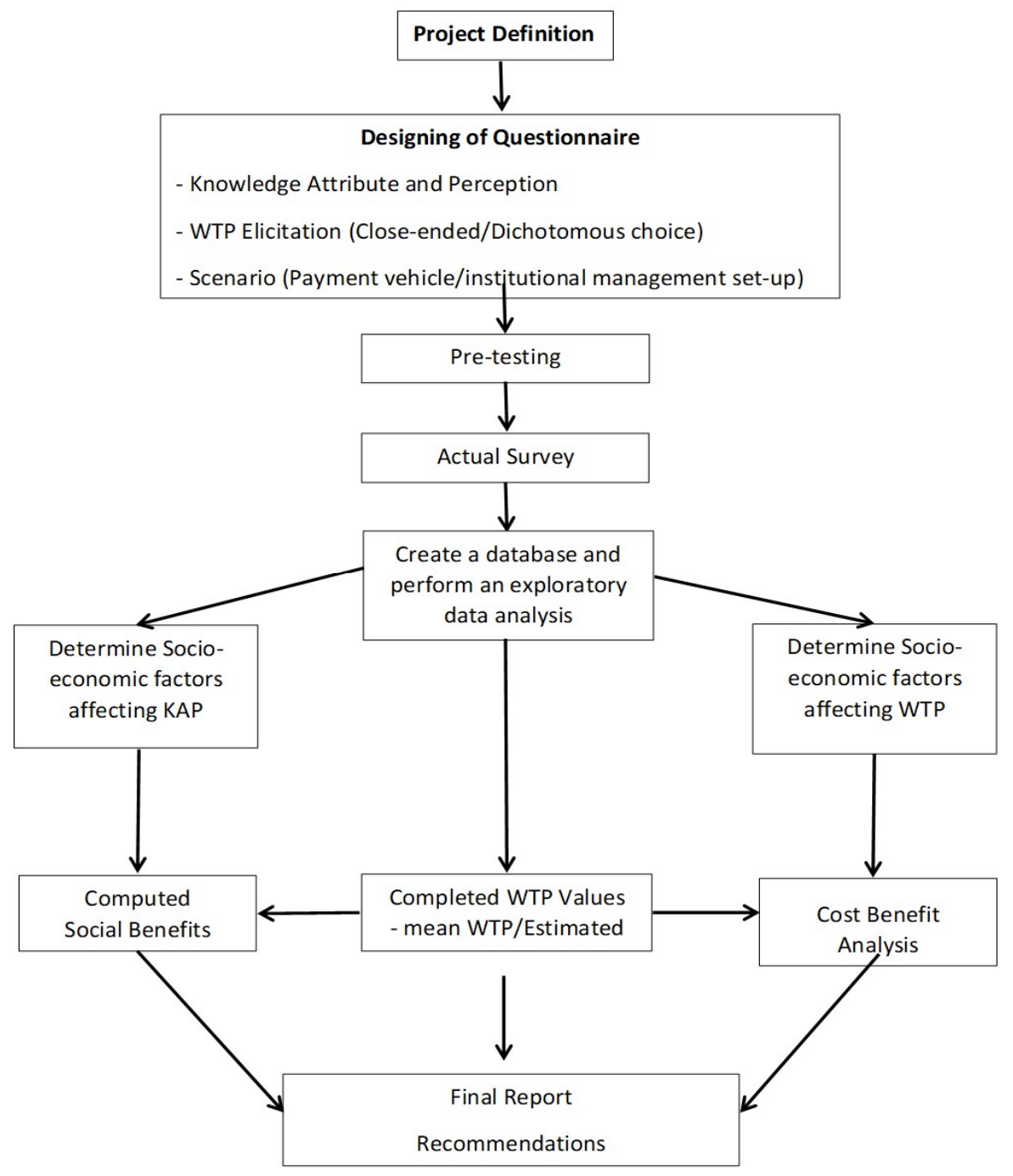

Figure II. Methodological framework of the study

\subsection{Survey Instrument Development}

The key importance of a contingent valuation study is a questionnaire that is designed properly such that the respondents have understood the questions well (Ureta et al., 2014).

Prior to the drafting of the survey instrument, a Focus Group Discussion was conducted through roleplaying. Maximum and minimum bid prices were obtained from this activity. The pretest was also performed to generate the appropriate and final bid amounts to finalize the questionnaire. The bid amounts generated from the pretest activity were Php 10.00, Php 40.00, Php 70.00, and Php 100.00, respectively. These amounts were used during the conduct of the survey.

\subsection{Survey Questionnaire Design}

The survey questionnaire is composed of three sections, namely: Knowledge Attitude and Perception, Willingness to Pay Elicitation, and Socio-economic characteristics of the household. 


\subsection{Knowledge, Attitude and Perception}

A total of 316 respondents were randomly selected. Prior to the interview, written consent was obtained from the respondents. The content of the questionnaire was based on related literature. A 5-point scale was used in the questionnaire. The higher the score, means more actions and solutions based on the data collected were required. For knowledge, a higher rating indicated that the community was knowledgeable about the benefits they could have from the establishment of Mataasna Bayan and Sinisian East Marine Protected Area. With regard to attitudes toward the said MPA, a higher rating indicated higher values were given for the conservation and protection of the area. It would also imply that they were not only getting the economic benefit from it but also giving high consideration to the environment as well. For the perception, a higher score showed the great importance of Mataasna Bayan and Sinisian East Marine Protected Area. Also, a higher rating indicated the need to expand the MPA, seeing its great contribution to the community's livelihood. Demographic data was also part of the questionnaire. A Focus group discussion was given to confirm and validate the acquired results from the survey.

\subsection{Determining the Willingness to Pay (WTP)}

In determining WTP, two major components were, two major components were involved: involved: 1) hypothetical scenario development; and 2) eliciting the Willingness to Pay for the expansion of MBSE MPA.

\subsection{The Scenario Setting}

A scenario to create the hypothetical market shall be constructed to illustrate the need to expand the MBSE MPA. This will involve increasing the core zone from 6.5 hectares to 16.5 hectares and expanding the buffer from 100 meters to 200 meters. This will need to allocate funds from the local government units, and hypothetically, to gather fee from the local community or every household of the Municipality of Lemery. The payment frequency will be every month and all year round. The time frame of the payment from the households will be only 10 years.

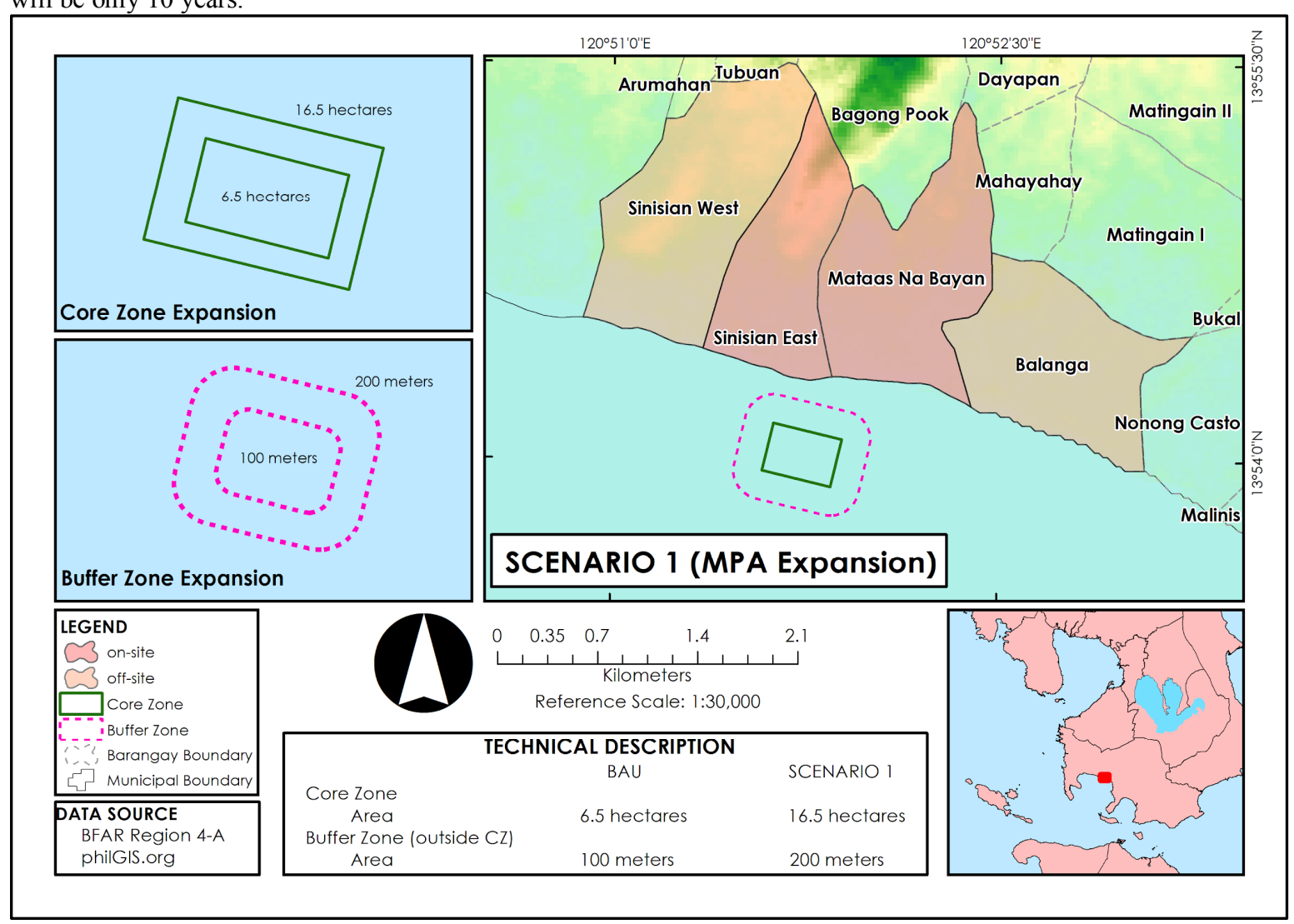

Figure III. Map showing the expansion scenario for the MAP area 


\subsection{Eliciting the Willingness to Pay}

In eliciting the willingness to pay, the dichotomous choice was utilized. There wasa range of amounts from lowest to highest starting from Php 10.00 to Php 100.00. The amount range was determined through a role play focus group discussion which represented by different sectors such as fishers, farmers, women, management body, LGU employee, and entrepreneurs. The total respondents were selected from the four barangays of Lemery Batangas: Mataasna Bayan and Sinisian East as on-site barangays and Barangays Balanga and Sinisian West as off-site barangays of the Marine Protected Area. To summarize, there were two on sites, and two off-sites, which are 352, were divided equally into each amount. The amounts were Php 10.00, Php 40.00, Php 70.00 and Php 100.00. There were four sets of respondents arranged according to the specific bid amount that was asked. In this case, the first set was asked for an amount of Php 10.00 (equally distributed to two on sites and two off-sites barangay, which is 22 respondents each). Then, the second set was asked for an amount of Php 40.00, and third and fourth sets were asked for the amount of Php 70.00 and Php 100.00, respectively. After that, the respondents were asked if they agree or disagree with paying for the specific bid amount (Wedgwood and Sansom, 2003).

In terms of the payment method or payment vehicle, respondents were asked on their preference on the payment method, which may be through the electric bill, water bill, other bills or any form of the annual fee that will contribute to the barangay.

\subsection{Socio-economic}

The study included the demographic and socio-economic variables of the surveyed household in MBSE MPA. The demographic and socioeconomic variables were the following: age, sex, civil status, educational attainment, occupation, number of household members, number of working/employed household members, income per month, estimated total expenses, years living in the area of MBSE, distance from the MPA, type of dwelling unit and household ownership.

\subsection{Data Analysis}

\subsubsection{Determining the significant variables to the responses of bidders}

Correlation analyses of Knowledge, Attitude, and Perception and socio-economic factors using ChiSquare, Variance-weighted Least Squares, and Kruskal-Wallis Test were done to determine its significance to the responses of the bidders.

\subsubsection{Determining the mean WTP of the households}

One way to analyze the expected output from binary choice situations (i.e., single-bounded dichotomous choice contingent valuation method) was used for the logistic regression model or simply, logit model (Hanemann, 1984; Hill, Griffiths, \& Judge, 2001; Koop et al., 2005; Tapsuwan\&Asafu-Adjaye, 2008; Hill, Griffiths, \& Lim, 2011) by STATA 11 software. This was a uni/multivariate technique that estimated the probability of the response, that is to occur or not, by predicting the binary dependent outcome from a set of independent variables expressed as (Hanemann, 1984):

$$
\log \left(p_{-} i /\left(1-p_{-} i\right)\right)=\beta \_0+\llbracket \beta^{\wedge^{\prime}} \mathrm{X} \rrbracket \_i
$$

where $\quad \mathrm{p}=$ probability of the response (either 1 or 0 )

$\mathrm{I}=$ index of respondents $(1,2,3, \ldots, \mathrm{N})$

$\mathrm{X}=$ significant variable

$\beta=$ unknown regression coefficient

Results of the regression analysis were then used to calculate the mean WTP, according to Hanemann (1994) equation:

$$
\text { mean } \mathrm{WTP}=(1 / \mid \beta \text { BidAmount } \mid)(\ln (1+e \alpha))
$$

where: $\mid \beta$ BidAmount $\mid=$ the absolute value of the bid amount's coefficient

$e \alpha=$ is the exponential function of alpha (i.e., the sum of all the products of coefficients and means of the significant variables) 


\section{RESULTS AND DISCUSSIONS}

\subsection{Socio-Economic Factors Affecting KAP}

Table 1 lists the coefficient, mean, and product of the significant independent variables and constant derived using STATA11 software. Five of the fifteen significant variables are positively correlated with WTP. Three KAP variables including knowledge on core zone, perception if MPA should be continued or not, and perception if there is anything to be changed in MPA management as well as two socio-economic variables such as residency, and distance from MPA are positively correlated with WTP. The increase in the aforementioned variables means that the respondents are more willing to pay for the expansion of the MBSE MPA. Conversely, the remaining ten significant variables, such as knowledge on MPA, perception on the need for MPA protection led by the barangay, household size, and household income generated negative coefficients, which indicate that these variables are inversely proportional with the respondents' willingness to pay.

Table 1 Summary of values for KAP and socio-economic variables as basis for computing WTP

\begin{tabular}{|c|c|c|c|}
\hline Variable & Coefficient & Mean & Product \\
\hline Knowledge on MPA & -0.1712467 & -0.4113924 & 0.070449591 \\
\hline Knowledge on core zone & 0.2232541 & -0.6424051 & -0.143419572 \\
\hline Knowledge on enforcement mechanism & -0.3348972 & 0.3037975 & -0.101740932 \\
\hline Knowledge on MPA's impact on fish production & -0.0324514 & 0.4050633 & -0.013144871 \\
\hline Knowledge on MPA as fish habitat & -0.1239688 & 0.4525316 & -0.056099799 \\
\hline Perception on the importance of core and buffer zones in protecting the MPA & -0.1053935 & 0.7056962 & -0.074375792 \\
\hline Perception on the need of MPA protection led by the Barangay & -0.0558382 & 1.199367 & -0.066970494 \\
\hline Perception if MPA should be continued or not & 0.5257913 & 1.525316 & 0.801997883 \\
\hline Perception if there is anything to be changed in MPA management & 0.1508764 & 2.31962 & 0.349975915 \\
\hline Gender & -0.7536253 & 1.724684 & -1.299765497 \\
\hline Household Size & -0.6157549 & 1.920886 & -1.182794967 \\
\hline Household Income & -0.00000252 & 12922.98 & -0.03256591 \\
\hline Income-Expenses Ratio & -0.000000912 & 7552.396 & -0.006887785 \\
\hline Residency & 0.014213 & 1.050633 & 0.014932647 \\
\hline Distance from the MPA & 0.0018003 & 2.428571 & 0.004372156 \\
\hline Constant & 0.9380223 & & \\
\hline$\alpha$ & & & 0.056085371 \\
\hline Mean WTP & \multicolumn{3}{|c|}{ PHP 46.46650551} \\
\hline Total Population (2015) & \multicolumn{3}{|r|}{1,792} \\
\hline Total Annual Benefit & \multicolumn{3}{|c|}{ PHP 999,215.734 } \\
\hline Total Benefit of the project (10 years) & \multicolumn{3}{|c|}{ PHP $12,910,327.46$} \\
\hline
\end{tabular}




\subsection{Socio-Economic and KAP Variables Influencing Willingness to Pay}

Results of the correlation analyses reveal that among the socio-economic and KAP variables, sixteen of them have significant relationships with the response of the bidders, especially to "yes" bidders. The following figures show how some of these variables influence their WTP.

\section{Perception of the "Yes" Bidders on the Need of MPA Protection Led by the Barangay (\%)}

$=\mathrm{D}$

$=$ NO

A

- SA

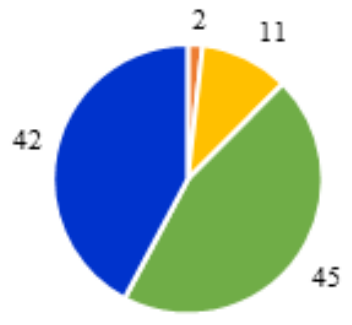

a.

\section{Perception of the "Yes" Bidders if there is Anything to be Changed in MPA Management (\%)}

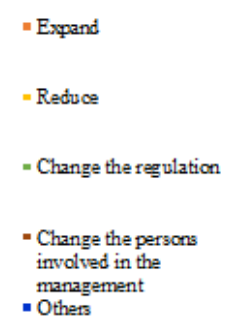

b.
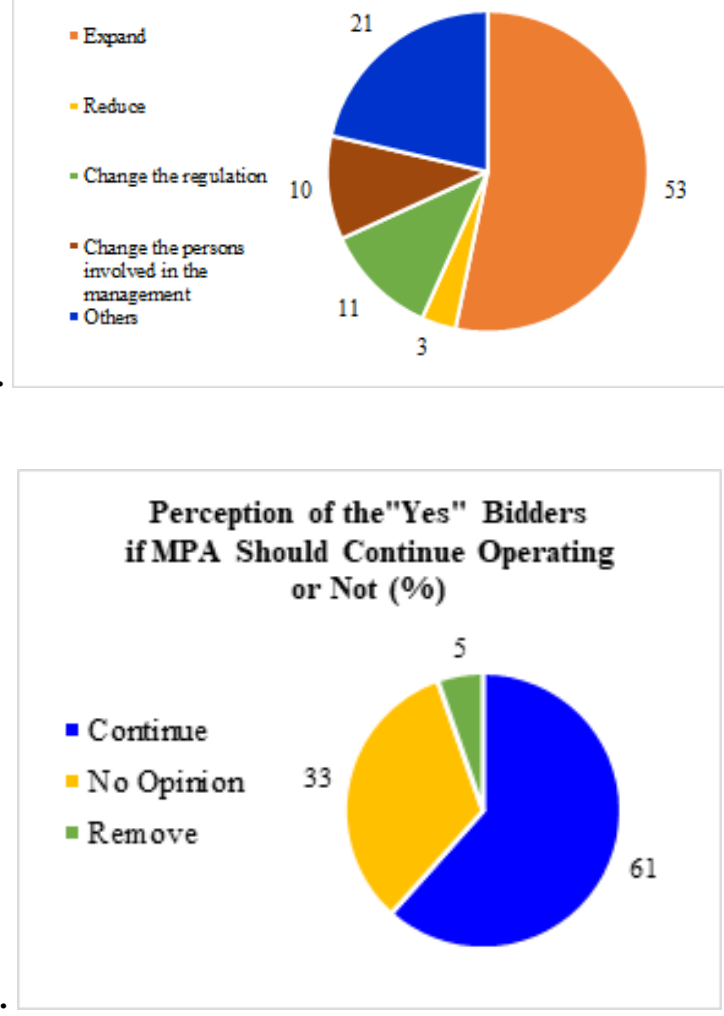


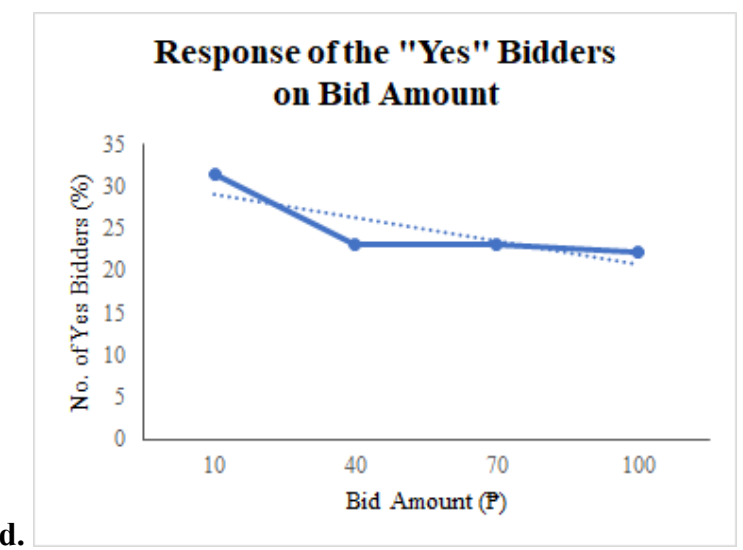

d.

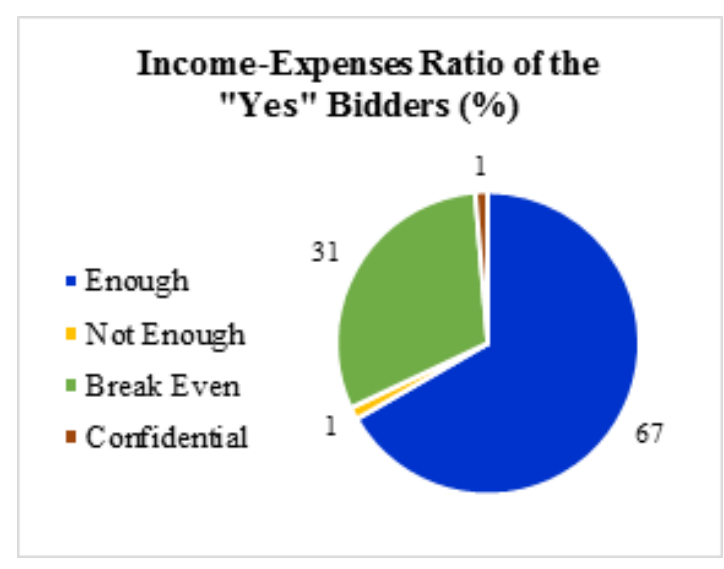

e.

\section{Residency of the "Yes" Bidders}

(\%)

\section{- Before the establishment of MPA \\ After the establishment of MPA}

f.

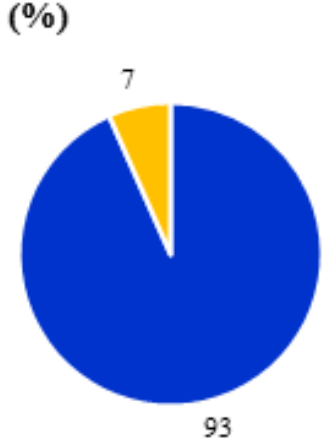




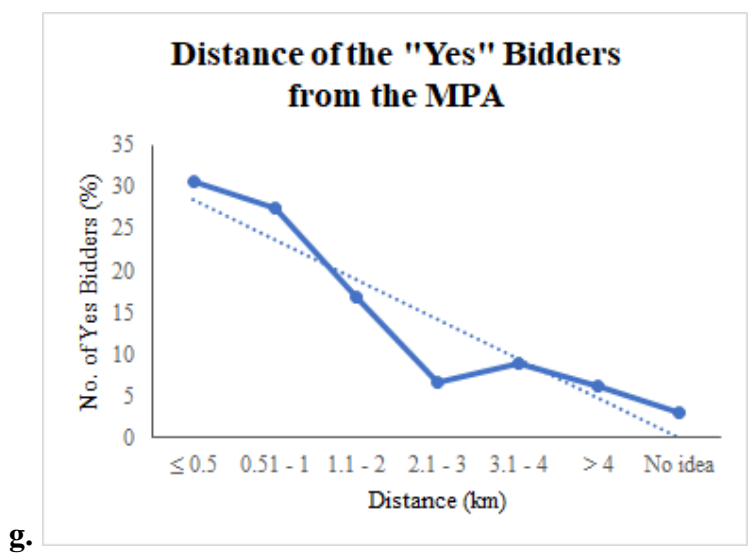

Figure a implies that as the perception on the need of that protection led by the Barangay increases, the number of yes bidders also increases. More than fifty percent of the total number of yes bidders believes that there is a need for MBSE MPA expansion (figure b) and said that it should continue operating (figure c). Moreover, figure $\mathrm{d}$ indicates that as the bid amount decreases, the number of yes bidders increases. In terms of the respondents' socio-economic profile, sixty-seven percent of the yes bidders said that their income-expenses ratio is enough (figure e). This strengthens their answers on their capability to pay. Also, ninety-three percent of the yes bidders have resided in the area even before the establishment of the MBSE MPA (figure f). This implies that the longer they have stayed in the area, the more they are willing to pay for the bid amounts. Finally, figure g reveals that as the distance of bidder's house from the MPA decreases, the number of yes bidders increases.

\subsection{Socio-economic Factors Affecting Knowledge, Awareness, and Perception}

Table 2 reveals the socio-economic factors that affect the knowledge and perceptions of the respondents on MBSE MPA. Livelihood affects the knowledge on enforcement mechanism while years in the barangay affects the knowledge on the impact of Marine Protected Area (MPA) on fish production and perception on the importance of core and buffer zones in protecting MBSE MPA.

The livelihood of respondents influences their knowledge on the enforcement mechanism since respondents engaged in fishing activities had higher knowledge on enforcement mechanisms, while non-fisher respondents are less aware of this. Respondents living in the barangay prior to MPA establishment in 2007 have higher knowledge on the impact of MPA on fish production and more positive perception on the importance of core and buffer zones in protecting MPA compared to respondents who started living in the barangay after the establishment of MPA in 2008.

Table 2 Socio-economic Factors Affecting Knowledge, Awareness and Perception

\begin{tabular}{|l|c|c|c|c|}
\hline \multicolumn{1}{|c|}{ Response } & Variable & Coefficient & p-value & Remarks \\
\hline Knowledge on Enforcement Mechanism & Livelihood & -1.084841 & 0.031 & Significant \\
\hline Knowledge on impact of MPA on fish production & $\begin{array}{c}\text { Years in the } \\
\text { Barangay }\end{array}$ & -1.168559 & 0.016 & Significant \\
\hline $\begin{array}{l}\text { Perception on the importance of core and buffer } \\
\text { zones in protecting MPA }\end{array}$ & $\begin{array}{c}\text { Years in the } \\
\text { Barangay }\end{array}$ & -1.555024 & 0.002 & Significant \\
\hline
\end{tabular}

\subsection{Mean Willingness to Pay of the Households}

The computed household expected mean WTP is Php 46.47 paid on a monthly basis for ten years. Results revealed that there is a $95 \%$ certainty that at this amount, the sampled population is willing to finance the expansion of MPA to increase its biodiversity. With a total of 1,792 total population of the four (4) 
barangays in 2015, the total annual social benefit of the project would amount to Php 999,215.734 and Php $12,910,327.46$ for the lifetime ( 10 years) of the biodiversity conservation project.

\section{CONCLUSION}

Based on the results, the researchers concluded the following:

- The resultant mean WTP is Php 46.47 paid on a monthly basis for ten years. Results revealed that there is a $95 \%$ certainty that at this amount, the sampled population is willing to finance the expansion of MPA to increase its biodiversity. With a total of 1,792 total population of the four barangays in 2015, the total annual social benefit of the project would amount to Php 999,215.734 and Php 12,910,327.46 for the lifetime (10 years) of the biodiversity conservation project.

- The socio-economic factors that can affect knowledge and perception of the respondents towards MPA are livelihood and years in the barangay. Livelihood affected knowledge on Enforcement Mechanism and years in the barangay affected knowledge on the impact of MPA on fish production and perception on the importance of core and buffer zones in protecting MBSE MPA.

\section{RECOMMENDATIONS}

\subsection{Policy/Decision Making}

- The consideration of WTP or monetized social benefit of the MBSE MPA in decision and policy making that can affect MPA.

- The socio-economic factors such as livelihood and years living in the barangay (before and after the establishment of MPA) that can influence the KAP of residents on MPA may be used as a basis on decision making with regards to increasing the awareness of residents about MPA.

- Increase IEC campaigns that can influence the KAP of the four Barangays about the MPA.

\subsection{MPA Management Effectiveness Enhancement}

- Formulation of a management plan by the MPA management board as their main basis for effective management of the MBSE MPA.

- Creation of Monitoring and Evaluation Plan of MPA implementation as basis for making management plan.

\subsection{Data Availability}

More intensive studies on the economic valuation of ecosystem services provided by MBSE MPA, such as annual fish production and coastal protection. Studies should explore the values of protecting or promoting other ecosystem services that may arise from the Marine Protected Area.

\section{Acknowledgments}

The authors would like to thank Dr. Rico C. Ancog for his unwavering support and guidance in the conduct of this study. The authors would also like to acknowledge the Barangay Chairmen of Barangays Balanga, Mataasna Bayan, Sinisian East, and Sinisian West, all in Lemery, Batangas for granting permission to conduct the study in their respective barangays and the Barangay Health Workers for extending necessary assistance during the survey procedure. The contribution of Mr. ArjayAfan for helping in the actual survey is also acknowledged.

\section{REFERENCES}

[1] Adjaye, J. \&Tapsuwan S. (2008). A Contingent Valuation Study of Scuba Diving Benefits: Case Study in Mu Ko Similan Marine National Park, Thailand, 26 (6), 1122-1130.

[2] Bateman, I., Carson, R.T., Day, B., Hanemann, M., Hanley, N., Hett, T., Jones-Lee, M., Loomes, G., Mourato, S., Ozdemiroglu, E., Pearce, D., Sugden, R.,\&Swanson, J. (2002). Economic Valuation with Stated Preference Techniques: A Manual.

[3] Buncag, M.J. (2019). Ecological Impact of Fishing and Tourism-Related Activities in San Vicente, Palawan, Philippines. International Journal of Science and Management Studies, 2 (6), 103-112 
[4] Edward Elgar Publishing, UK. https://doi.org/10.1016/j.ecolecon.2004.03.002

[5] Hall, D., Hall, J. \& Murray, S. (2002). Contingent valuation of marine protected areas: southern California rocky intertidal ecosystems. Rocky Mountain Mathematics Consortium. Natural Resource Modeling. Volume 15, Number 3, pp. 335-368.

[6] Hanemann, M. (1984). Welfare Evaluations in Contingent Valuation Experiments with Discrete Responses, 66 (3), $332-341$. Retrieved at https://econpapers.repec.org/scripts/redir.pf?u=http\%3A\%2F\%2Fhdl.handle.net\%2F10.2307\%2F1240800;h=repec:oup:ajagec:v:66:y: 1984:i:3:p:332-341.

[7] Hicks, C., McClanahan,T., Cinner, J.,\& Hills, J. (2009). Trade-offs in values assigned to ecological goods and services associated with different coral reef management strategies. Ecology and Society. 2009;14. Available in: https://www.ecologyandsociety.org/vol14/iss1/art10/main.html

[8] Hill, R., Griffiths, W. \& Lim, G. (2011). Principles of Econometrics. Retrieved at https://www.academia.edu/30183056/Hill_Griffiths_Lim_Principles_of_Econometrics

[9] Koop, G., Poirier, D. \& Tobias J. (2005). Semiparametric Bayesian Inference in Multiple Equation Models. Retrieved at https://doi.org/10.1002/jae. 810

[10] Municipal Planning and Development Council (2015). Lemery Community-based monitoring system report.

[11] Municipality of Lemery (n.d.). Socio-economic Assessment Tool (SEAT): Assessing the Socio-economic Benefits of Marine Protected Areas (MPAs).

[12] Municipality of Lemery (2013). VIP Management Effectiveness Assessment (METT) Results. MPA Result Presentation. Unpublished report.

[13] Ureta, J.C., Lasco, R., Sajise, A., \& Calderon, M. (2014). Oroquieta City Household's Willingness To Pay for Coastal Biodiversity Conservation, 7 (5), 82-92.

[14] Wedgwood, A. \& Sansom K. (2003). Willingness to Pay Surveys- A Streamlined Approach. Loughborough University.

[15] Weeks, R., Russ, G., Alcala, A,\& White, A. (2010). Effectiveness of Marine Protected Areas in the Philippines for Biodiversity Conservation. Conservation Biology Volume 24, Issue 2, Pages 531-540. https://doi.org/10.1111/j.1523-1739.2009.01340. 